\title{
O ECOTURISMO E A PLANIFICAÇÃO DA GESTÃO AMBIENTAL NO DESENVOLVIMENTO DE ESTRATÉGIAS EM ÁREAS NATURAIS PROTEGIDAS ${ }^{1}$
}

\author{
http://dx.doi.org/10.21527/2176-6622.2020.54.77-90
}

Recebido em: 13/12/2019

Modificações solicitadas em: 20/4/2020

Aceito em: 20/7/2020

\section{RESUMO}

\section{Magno Federici Gomes}

Estágio Pós-Doutoral em Direito Público e Educação pela Universidade Nova de Lisboa-Portugal (Bolsa Capes/ BEX 3642/07-0). Estágios Pós-Doutorais em Direito Civil e Processual Civil. Doutor em Direito e Mestre em Direito Processual pela Universidad de Deusto-Espanha (Bolsa da Cátedra Unesco e do Gobierno Vasco-Espanha). Mestre em Educação pela PUC Minas. Professor do Doutorado e Mestrado Acadêmico em Direito Ambiental e Desenvolvimento Sustentável na Escola Superior Dom Helder Câmara. Professor titular licenciado da Faculdade de Direito Arnaldo Janssen. Advogado sócio do Escritório Moraes \& Federici Advocacia Associada. Líder do Grupo de Pesquisa: Regulação Ambiental da Atividade Econômica Sustentável (Rega)/CNPQ-BRA e integrante dos grupos: Centro de Investigação \& Desenvolvimento sobre Direito e Sociedade (Cedis)/FCT-PT, Núcleo de Estudos sobre Gestão de Políticas Públicas (Negesp)/CNPQ-BRA e Metamorfose Jurídica/CNPQ-BRA. http://lattes.cnpq. br/1638327245727283. http://orcid.org/0000-0002-4711-5310. magnofederici@gmail.com

\section{Joana Rita Gomes Gonçalves}

Mestranda em Direito Ambiental e Desenvolvimento Sustentável na Escola Superior Dom Helder Câmara. Licenciada em Solicitadoria pelo Instituto Politécnico do Cávado e do Ave, Portugal. http://lattes.cnpq. br/0522192915428622. joanaggoncalves95@gmail.com

O tema desta pesquisa é ecoturismo enquanto modalidade de turismo sustentável preservacionista dos recursos naturais, da biodiversidade e da vida selvagem, que, embora seja importante, há certa dificuldade na sua consolidação. O objetivo da presente pesquisa pauta-se em estabelecer meios viáveis e eficazes para seu estabelecimento. Assim, pretende-se responder se o ecoturismo pode ser um instrumento de efetivação do desenvolvimento sustentável e da proteção ambiental. Para tanto, a metodologia usada foi a bibliográfica e documental com raciocínio dedutivo. Conclui-se que os objetivos do ecoturismo deverão ser seguidos em conjunto pelas comunidades e pelos governos locais, por meio do desenvolvimento de estratégias e planejamento para que se alcancem as dimensões social, ambiental e econômica da sustentabilidade.

Palavras-chave: Ecoturismo. Gestão e planejamento ambientais. Desenvolvimento sustentável. Áreas protegidas.

ECOTOURISM AND PLANNING ENVIRONMENTAL MANAGEMENT IN THE DEVELOPMENT OF STRATEGIES IN PROTECTED NATURAL AREAS

\section{ABSTRACT}

The theme of this paper is the ecotourism, as a sustainable tourism modality that preserves natural resources, biodiversity and wildlife, which, although important, has some difficulty in its implementation. The aim of this paper is to establish viable and effective means for this implementation. Thus, it is intended to answer whether ecotourism can be an instrument for effecting sustainable development and environmental protection. For this, the methodology used was bibliographic and documentary with deductive reasoning. It is concluded that the objectives of ecotourism should be pursued together, by communities and local governments, through the development of strategies and planning to reach the social, environmental and economic dimensions of sustainability.

Keywords: Ecotourism. Environmental management and planning. Sustainable development. Protected areas.

\section{SUMÁRIO}

1 Introdução. 2 Gestão ambiental. 2.1 Convenções da Diversidade Biológica e sobre a Mudança Climática. 2.2 União Europeia. 2.3 Mercado Comum do Sul. 3 Ecoturismo. 3.1 Evolução histórico-social do ecoturismo. 4 Ecoturismo como atividade do futuro. 4.1 Base principiológica do turismo sustentável pela Organização das Nações Unidas e Organização Mundial do Turismo. 4.2 Planejamento ecoturístico em áreas naturais de preservação. 4.3 Definição de diretrizes para o diagnóstico e planejamento do ecoturismo e a participação social. 5 Considerações finais. 6 Referências.

\footnotetext{
1 Trabalho financiado pelo Projeto Fapemig no 22869, resultante dos Grupos de Pesquisas (CNPQ): Regulação Ambiental da Atividade Econômica Sustentável (Rega), Negesp, Metamorfose Jurídica e Cedis (FCT-PT).
} 


\section{INTRODUÇÃO}

A intervenção humana no meio ambiente, por meio de suas ações antrópicas, mais aguda desde a revolução industrial, se fez sentir com maior intensidade no final do século passado, em razão do aumento dos níveis de $\mathrm{CO}_{2}$ na atmosfera.

A Conferência de Estocolmo de 1972 foi a primeira grande reunião, realizada pela Organização das Nações Unidas (ONU), com a pretensão de discutir acerca das questões que cercam os problemas causados pelo homem ao meio ambiente e desenvolver diretrizes na direção e compromissos na defesa do meio natural.

A conferência supramencionada teve suma importância, uma vez que reuniu diversos países para tratar da viabilização do desenvolvimento sustentável, e foi, a partir dela, que as questões relacionadas ao meio ambiente passaram a ser consideradas de forma mais firme no mundo, embora ainda restasse certa dificuldade em encontrar medidas efetivas para a execução do que foi debatido na ocasião.

É nessa seara que se desenvolve o ecoturismo, como resultado da necessidade de se repensar a relação do ser humano com o meio que o rodeia para além de uma visão puramente instrumental, sendo ele o tema deste trabalho.

O objetivo da investigação é caracterizar o ecoturismo desde a sua origem e inseri-lo no desenvolvimento sustentável, que considere as suas diversas vertentes, para, finalmente, estabelecer instrumentos eficazes para sua instituição.

Os problemas que se pretendem responder neste artigo são: Poderá o ecoturismo constituir uma alternativa viável para a proteção ambiental e para o desenvolvimento sustentável? Políticas que envolvam as comunidades locais poderiam alcançar um crescimento econômico, capaz de preservar o meio natural e promover um desenvolvimento sustentável?

Embora seja uma reflexão urgente e necessária, que precisa ser feita nos dias atuais, dada a situação cinzenta que o planeta vem enfrentando de superexploração dos seus recursos, cuja preservação e conservação são essenciais para a manutenção da vida na Terra, há atualmente certa dificuldade para efetivação do ecoturismo, uma vez que, além de ser impossível se distanciar de todos os impactos negativos, a sua viabilidade demanda atuação conjunta entre comunidade e governo local. Além disso, é também necessária a reformulação dos valores, comportamentos e atitudes da população.

O método de pesquisa utilizado para a elaboração do presente trabalho foi o bibliográfico e documental, por meio da análise de teorias que retratam o ecoturismo como uma opção viável para a proteção ambiental, com técnica dedutiva. Também foram utilizados documentos e estatísticas de organizações internacionais não governamentais (ONGs).

A seguir é analisada a Convenção da Diversidade Biológica (CDB), criada no ano de 1992 para a proteção da biodiversidade e dos conhecimentos dos povos tradicionais, da mesma forma que é examinada a Convenção sobre a Mudança Climática (UNFCCC), elaborada no ano de 1994 para a estabilização da emissão de Gases de Efeito Estuda (GEE). O direito comunitário da União Europeia (UE) e do Mercado Comum do Sul (Mercosul) serão analisados na sua vertente ambiental, criada somente após a chancela dos tratados que instituíram cada um dos direitos comunitários, pela preocupação primeira com a estabilização da economia dos países signatários.

Na sequência inicia-se uma exposição acerca da evolução histórico-social do ecoturismo, posto que, num primeiro momento, critica-se a tecnociência pela visão puramente instrumental que ela confere ao meio ambiente.

No terceiro item desenvolve-se a ideia do ecoturismo como atividade do futuro, a sua base principiológica na concepção da ONU e da Organização Mundial do Turismo (OMT), no qual serão desenvolvidos, ainda que não exaustivamente, os 12 princípios que regem o ecoturismo à luz dessas duas organizações. O planejamento ecoturístico em áreas naturais de preservação procurará delinear a importância do desenvolvimento de planos de gerenciamento prévios que considerem as diversas áreas de intervenção, quais sejam: infraestruturas, estradas, setor hoteleiro e saneamento, mostrando também o desempenho do turismo no plano econômico global. A definição de diretrizes para o diagnóstico e a participação social são entendidas com base nos Objetivos do Desenvolvimento Sustentável (ODS), essenciais para uma efetivação do ecoturismo. 


\section{GESTÃO AMBIENTAL}

O conceito de desenvolvimento sustentável surgiu em 1987 com o Relatório da Comissão de Brundtland, ${ }^{2}$ denominado "Nosso Futuro Comum", com a seguinte denominação: "a capacidade de atender as necessidades das gerações presentes sem comprometer a capacidade das gerações futuras satisfazerem as suas próprias necessidades" (UNITED NATIONS, 1987); denominação que sofreu algumas críticas por parte de ambientalistas e conservacionistas, pela sua dimensão puramente econômica associada à sustentabilidade e à visão da sustentabilidade como desenvolvimento.

Nesta parte pretende-se desenvolver mais sobre essas questões acerca do desenvolvimento sustentável, da biodiversidade e as consequências das ações humanas no clima.

\subsection{Convenções da Diversidade Biológica e sobre a Mudança Climática}

A Convenção da Diversidade Biológica e sobre a Mudança Climática (CDB), também assim denominada, foi instaurada no ano de 1992 durante a ECO-92 - Conferência das Nações Unidas para o Meio Ambiente e Desenvolvimento (CNUMAD), realizada no Rio de Janeiro, com 188 países que a ratificaram, com objetivos gerais relacionados à conservação da biodiversidade, promoção do manejo sustentável dos recursos naturais, repartição equitativa dos benefícios auferidos entre os países detentores dos recursos e os detentores do conhecimento científico, acesso apropriado aos recursos e transferência de tecnologia, tendo como princípio base o da soberania, por meio do qual qualquer Estado tem o direito de explorar os recursos existentes no seu território sem que, com isso, os outros países tenham o seu direito a um meio ambiente ecologicamente equilibrado, prejudicado.

Dessa forma, a CDB não só debateu as questões relacionadas à conservação do meio ambiente, mas incluiu, em seus objetivos, o desenvolvimento social e econômico, o que é extremamente importante, uma vez que é indispensável que ambas as dimensões sejam aliadas para que viabilizem medidas eficazes.

A Convenção-Quadro das Nações Unidas sobre as Mudanças Climáticas (CQNUMC), também conhecida como UNFCCC, ${ }^{3}$ igualmente criada durante a ECO-92 no Rio de Janeiro, adotou como objetivo a estabilização da concentração dos Gases do Efeito Estufa - GEE -, em razão do seu potencial efeito negativo sobre a atmosfera e o clima terrestre. ${ }^{4}$

Por ser uma questão que demanda colaboração de todos os países, as partes da Convenção-Quadro assumiram alguns deveres de soft law, como o "princípio da responsabilidade comum, porém diferenciada", comprometendo-se a assumir a proteção do sistema climático, preservando-o para as futuras gerações conforme a capacidade de cada parte, cuja responsabilidade dessa ação deve abranger também os países mais vulneráveis, que sofrem mais com as mudanças climáticas.

Cabe destacar o Tratado do Protocolo de Kyoto como uma ação complementar à Convenção-Quadro, que veio a ser consolidado em 1997. Foi criado um conjunto de mecanismos que preveem metas para a redução de GEE e do efeito estufa causado pelas atividades humanas, além do aumento da utilização de Fontes de Energia Renovável (FER), em uma tentativa de crescimento da eficiência energética. $O$ tratado é um pacto firmado entre as partes, quando elas se comprometem "(...) a diminuir em 5,2\% a emissão dos gases que dão causa ao aquecimento global, tendo por base a emissão verificada nos anos 90" (CERON; PORTO, 2013, p. 532), e, por isso, mantêm um caráter de obrigatoriedade, ao contrário da Convenção-Quadro.

Ainda na ECO-92, foram consolidados os princípios criados na oportunidade por meio da elaboração de uma agenda, a Agenda 21. Ela foi criada a fim de estabelecer medidas a serem adotadas pelos países ao longo do século 21, para estabelecer o desenvolvimento sustentável mundial mediante ações de monitoramento e consolidação dos acordos elaborados nos âmbitos locais, regionais e globais.

\footnotetext{
2 Denominação dada em homenagem à ministra do Ambiente da Noruega, Gro Harlem Brundtland.

3 Em inglês: United Nations Framework Convention on Climate Change (UNFCCC).

4 No ano de 1992 realizava-se no Rio de Janeiro a Conferência das Nações Unidas para o Desenvolvimento Sustentável (Rio 92 , ECO-92 ou Cúpula da Terra), com o objetivo de traçar um compromisso numa agenda global para o combate às catástrofes ambientais da presente década e décadas anteriores.

5 Segundo BRASIL, 2019.
} 
Cabe salientar que a Agenda 21 também buscou uma educação ambiental por parte da sociedade, porque, embora demande participação ativa das autoridades governamentais, inclusive locais, a comunidade em geral é elemento essencial para as mudanças na esfera ambiente. Nesse sentido, destaca Machado et al. (2007):

Em específico, a Agenda 21 estimula acontecimentos como projetos da coletividade ou populares, estratégias de intervenção política e organização social que, se permeados por uma prática educativa crítica e uma concepção de ambiente enquanto projeto comunitário, poderão mudar comportamentos e valores e, por conseqüência, cenários e fatos insustentáveis (p. 109).

Mais tarde, em 2015, na cidade de Nova York, os objetivos para se alcançar o desenvolvimento sustentável reformularam-se em uma nova agenda, a Agenda 2030. ${ }^{6}$ Por meio dela foram consolidados os Objetivos do Desenvolvimento Sustentável - ODS -, no sentido da elaboração de inventários de âmbito nacional e sua publicação no que se refere às emissões verificadas, elaboração de programas de âmbito nacional e também regional para a efetivação do controle e para a mitigação dos efeitos resultantes dessas emissões, além de promoção de gerenciamento sustentável, assim como da educação e da conscientização pública para a preservação do meio ambiente enquanto bem de uso comum do povo.

Os objetivos foram traçados como forma de metas a serem cumpridas pelos países até 2030. Cabe salientar que, diferente da Agenda 21, criada na ECO-92, a Agenda 2030 foi mais específica, ao incluir em seus objetivos a erradicação da pobreza extrema e, consequentemente, a fome, bem como a educação efetiva, o avanço na saúde e a igualdade de gênero. ${ }^{7}$

\subsection{União Europeia}

No âmbito europeu, relativamente às questões acerca do desenvolvimento sustentável e mudanças climáticas, é perceptível um avanço significativo nos dias atuais, mas nem sempre foi assim. A Comunidade Econômica Europeia (CEE) - Tratado de Roma -, criado no ano de 1957, não fez qualquer menção à questão ambiental, uma vez que seu foco naquele momento era na reconstrução da economia que se encontrava seriamente prejudicada pela Segunda Guerra Mundial. Essa discussão apenas veio a ser retratada em 1972, ano da Conferência de Estocolmo, na qual se criou o Programa das Nações Unidas para o Meio Ambiente (PNUMA), com objetivo de monitorar o meio ambiente global e informar à sociedade a respeito da situação ambiental mundial e as medidas cabíveis para sua melhoria.

No ano de 1987, o Ato Único Europeu (AUE), ${ }^{8}$ documento assinado em Luxemburgo, alterou o Tratado de Roma, definindo, no âmbito europeu, as primeiras diretrizes protetivas para o meio ambiente, saúde, segurança e defesa do consumidor. Além disso, delineou a vinculação da Comunidade Europeia, por meio da fixação de competências ambientais e medidas protetivas e preservacionistas do meio ambiente com base nos princípios do poluidor-pagador e da prevenção.

Com o Tratado de Maastritch, que instituiu a União Europeia (UE) em 1992, foram mantidos os anteriores ideais de preservação ambiental. Acrescentou-se, entretanto, a ideia de que o crescimento econômico deveria ser sustentável, respeitando, assim, a capacidade de reposição dos recursos naturais. ${ }^{9}$ Dessa forma, é necessário destacar que o tratado, diferente do AUE, eleva as questões ambientais a um patamar de políticas públicas e gestão efetiva cumulados com a movimentação da sociedade em prol do desenvolvimento sustentável. ${ }^{10}$

\footnotetext{
6 Conforme NAÇÕES UNIDAS BRASIL, 2015.

7 Para aprofundamentos na relação entre políticas públicas e os objetivos do desenvolvimento sustentável, ver: GOMES; FERREIRA, 2018, p. 155-178.

8 Ver: PARLAMENTO EUROPEU, 1987.

9 Ideia que se confunde com o plexo de sustentabilidade sugerido por GOMES; FERREIRA, 2017, p. 93-111; GOMES; FERREIRA, 2018 , p. $155-178$.

${ }^{10}$ É o que se objetiva no texto de GOMES; FERREIRA, 2018, p. 155-178.
} 
Um exemplo de gestão ambiental efetiva foi instaurada por meio da Diretiva 94/62 de 20 de dezembro de 1994 da Comunidade Europeia, que promove a reutilização de embalagens. A Diretiva procurou dar resposta para a necessidade de harmonizar as diferentes disposições e medidas nacionais no que diz respeito à gestão das embalagens e dos seus resíduos, com o objetivo de se proteger o meio ambiente ${ }^{11}$ e de assegurar o funcionamento do mercado interno da comunidade, procurando se evitar entraves comerciais e concorrência.

O objetivo principal era reduzir a quantidade global de embalagens, com um papel significativo de cada Estado-Membro, no sentido de que as medidas adotadas por eles não deveriam prejudicar a capacidade de os outros Estados-Membros cumprirem com os objetivos da Diretiva ${ }^{12}$. Para tanto, as empresas privadas, públicas e até de Parcerias Público-Privadas (PPP), assumem um caráter incentivador de grandes dimensões.

Um outro exemplo de gestão ambiental ocorreu em Portugal. A Sociedade Ponto Verde (SPV), criada em 1996, teve como finalidade a reciclagem de plásticos, vidros, papéis e outros materiais para introdução da sustentabilidade e da inovação quanto à resíduos plásticos. A Sociedade comprometeu-se com a Circular Plastics Alliance a reunir o público e o privado na garantia da reciclagem de 10 milhões de toneladas de plásticos até $\mathrm{o}$ ano de 2025. Do compromisso fazem parte 50 stakeholders e a PROsPA (Producer Responsability Organisations Packaging Alliance).

\subsection{Mercado Comum do Sul}

Por sua vez, na América do Sul, o Mercosul, criado em 1991, da mesma forma que a União Europeia, na sua origem atentou-se apenas na criação de uma união aduaneira e comercial entre alguns países da América do Sul, dentre os quais Argentina, Brasil, Paraguai e Uruguai.

Por visar a perspectivas meramente econômicas, o Tratado de Assunção de 1991, que efetivamente criou o Mercosul, apenas concedeu breve consideração ambiental no seu preâmbulo. Apenas em 1994, com a aprovação da Recomendação 01/94, que viria a se tornar a Resolução 10/94 ${ }^{13}$ do Grupo do Mercado Comum (GMC), órgão com competência executiva, estabeleceram-se as primeiras diretrizes básicas relacionadas com o tema no que diz respeito a licenciamento ambiental, custos ambientais e sua internalização e à harmonização de legislações ambientais dos países componentes do Mercosul.

No ano de 2001 foi firmada a Resolução no 2/01, denominada Acordo-Quadro sobre Meio Ambiente (AQMA) entre os países, com o intuito de ressaltar o compromisso com as questões decididas pela ECO-92. A Resolução abrangeu pretensões relacionadas ao desenvolvimento sustentável nas suas dimensões econômica, social e ambiental. ${ }^{14}$ Nele, procurou-se, por meio da inclusão entre o ambiental e o econômico, promover a proteção ambiental mediante políticas setoriais, inclusão e prioridade por intermédio da participação popular das questões ambientais nas tomadas de decisão no Mercosul.

Dessa forma, as áreas de atuação por parte dos países concentravam-se em quatro aspectos: gestão e manejo sustentável dos recursos naturais, qualidade de vida e planejamento ambiental com incidência no tratamento residual, instrumentos de política ambiental no que se refere à legislação eficaz e eficiente, avaliação e gerenciamento ambiental e, por fim, atividades produtivas e ambientalmente sustentáveis nas quais se destacam o ecoturismo, tema a ser desenvolvido.

É importante salientar que no ano de 2004 houve uma complementação do AQMA, por meio de protocolo que dirime acerca de questões emergenciais ambientais eventualmente vivenciadas pelos países componentes. Nessa complementação, foi estabelecida a cooperação entre os Estados-membros em caso de desastres ambientais.

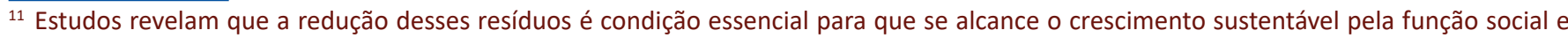
econômica que representam.

12 Dentre os principais objetivos da diretiva, previa-se como medida a ser adotada até 2001 um aproveitamento de $50 \%$ a $65 \%$ dos resíduos das embalagens, reciclagem de $25 \%$ a $45 \%$ das embalagens e um mínimo de $15 \%$ de cada um dos materiais das embalagens.

${ }^{13}$ Que, diferentemente do que acontece com as Recomendações da UE, que assumem aplicabilidade imediata e direta aos Estados-membros quando dispõem de questões legislativas, as resoluções deste grupo necessitam da aprovação dos países membros do Mercosul para que assumam caráter vinculativo aos restantes Estados.

${ }^{14}$ Sabe-se que existem outras dimensões do desenvolvimento sustentável, conforme: GOMES; FERREIRA, 2017, p. 93-111.
} 


\section{ECOTURISMO}

Foi demonstrado, com o presente artigo, uma evolução das questões ambientais no âmbito internacional e regional, mediante a apresentação das principais discussões sobre o meio ambiente e o desenvolvimento sustentável. Dessa forma, conclui-se, desde já e preliminarmente, que os Estados devem adotar medidas para diminuir os impactos ambientais provenientes das ações do homem, de forma ampla o suficiente para abranger os aspectos econômicos e sociais por meio de uma gestão ambiental efetiva.

A finalidade da tratativa dos dispositivos normativos internacionais, portanto, foi introduzir a importância do meio ambiente equilibrado e sustentável e os modos pelos quais isso se torna possível.

Assim, uma importante política socioeconômica-ambiental, que será abordada neste item, é o Ecoturismo, como um meio alternativo para se manter e preservar a biodiversidade.

Antes, é necessário um estudo histórico para demonstrar a sua evolução e como suas ações podem contribuir no cenário de degradação ambiental.

\subsection{Evolução histórica do Ecoturismo}

Em detrimento das catástrofes ambientais ocorridas ao longo do século 20, dentre as quais o vazamento radioativo em Chernobyl, no ano de 1985, e o Exxon Valdez, no ano de 1989, ${ }^{15}$ tornaram-se necessária tomadas de decisão para que a qualidade do meio ambiente não fosse mais comprometida.

Nesse sentido, questionando-se sobre o papel do ser humano na Terra e a sua relação com o meio ambiente, Rachel Carson publicou a sua obra "Primavera Silenciosa" no ano de $1962,{ }^{16}$ propondo sério questionamento acerca do antropocentrismo.

O tecnocentrismo, ou o "ambientalismo tecnológico", surge aliado à ideia de que a ciência e o conhecimento tecnológico poderão libertar a humanidade dos efeitos nefastos que as alterações climáticas estão a provocar nos sistemas de vida. A tecnologia, criada pelo ser humano com a matéria-prima fornecida pelo meio natural, desenvolve na humanidade uma sensação de conforto e de confiança que a levam a crer que a vida no planeta não estará comprometida enquanto houver a capacidade de inovar e métodos e recursos para isso. A convicção de que a ciência soluciona os problemas com base nas leis da física, é a base da instrumentalização do meio ambiente enquanto meio para os fins propostos pelos humanos.

Ante tantas atrocidades, dentre as quais algumas já elencadas, surgiram os movimentos verdes, ambientalistas ou ecoturistas, que procuravam uma solução ou uma mitigação dos problemas a que o meio ambiente era exposto. Os ecoturistas ${ }^{17}$ salvaguardam a conservação da natureza como valor intrínseco em si mesmo, independentemente dos fins utilitários que pode oferecer.

Numa perspectiva ecocêntrica, o meio ambiente surge como fim em si mesmo, como palco da sensibilidade, como um organismo vivo que se desenvolve num sistema único e uníssono. Poder-se-ia até enriquecer este conceito com base na tese da ecologia profunda (deep ecology), ${ }^{18}$ num entendimento holístico da natureza, numa relação intrínseca entre o humano e a natureza, numa relação perfeitamente harmônica e sintonizada, uma extensão do ser humano.

A ecologia profunda, segundo Jonge (2004, p. 26), representa quatro princípios essenciais relacionados com o questionamento da ligação do ser humano com a natureza: a metafísica da ética ambiental, o movimento político com premissas descritivas e normativas e o ativismo ante a destruição massiva da natureza.

\footnotetext{
$\overline{15}$ Trata-se do maior desastre petrolífero: derramamento de óleo do Exxon Valdez, que jogou 40 milhões de litros de petróleo bruto em Prince William Sound, no Alasca.

${ }^{16}$ A autora apresentou uma importante discussão sobre o uso incontrolado dos inseticidas, sem nenhum controle sobre as substâncias químicas, tal como o Dicloro-Difenil-Tricloroetano (DDT), hoje banido dos EUA.

${ }^{17}$ Neste sentido destaca-se uma diferenciação feita entre ecoturistas "verdes claros" e "verdes escuros". A diferença entre ambos reside no fato de os primeiros colocarem o seu conforto acima da conservação da natureza. Já os segundos, colocam a conservação ambiental acima do seu conforto (WEARING; NEIL, 2014, p. 24).

${ }^{18}$ Termo criado pelo filósofo norueguês Arne Naess (1912-2004) como a corrente que defende a interligação entre o ser humano e o meio que o rodeia, relação essa que incitará a redução dos impactos da nossa existência no meio natural, numa utilização dos recursos que atenda ao sustento e à satisfação das necessidades vitais.
} 
Ao encontro dos preceitos elencados, os ecoturistas defendem a conservação do meio ambiente na sua forma natural, numa abordagem não intervencionista ou com os menores impactos possíveis, num encontro à teoria da ecologia profunda de forma rigorosa. Uma abordagem em torno da "tecnologia suave" considera o humano na sua inter-relação e interdependência com o meio natural, pelo que o homem atuaria como administrador da natureza, numa perspectiva preservacionista (WEARING; NEIL, 2014, p. 31).

A estrutura tecnocêntrica procura soluções que se situam no âmbito técnico para problemas econômicos, sociais e ecológicos, que exige, para além de mudanças técnicas, mudanças de valores no modo como se valora a natureza, como instrumento ou como fim em si mesma.

Hardin (1968), na sua obra "The tragedy of the commons", retratava o problema da propriedade coletiva dos recursos naturais. Segundo ele, tudo aquilo que é de todos não é de ninguém, pelo que, nessa perspectiva, o seu uso seria ilimitado perante o uso que cada ser Ihes quisesse dar. Essa coletividade dos recursos naturais levou a que os mesmos fossem superexplorados. Quando se adota essa posição no que se refere ao ecoturismo, as empresas que ficariam por trás dos projetos e empreendimentos poderiam atuar de modo a obter o lucro máximo, sem considerar a sustentabilidade que se pretende alcançar com projetos ecoturísticos. 0 mesmo poderia acontecer com relação à violação da capacidade de carga ${ }^{19}$ de um determinado espaço, para que, com um maior índice de densidade populacional, fosse possível um aumento no ganho econômico.

Quanto ao aumento do turismo sustentável, definido pela $\mathrm{OMT}^{20}$ como o "turismo que leva em consideração os seus impactos econômicos, sociais e ambientais atuais e futuros, atendendo às necessidades dos visitantes, da indústria, do meio ambiente e das comunidades anfitriãs", em âmbito global dados registraram um aumento significativo desse número após o término da Segunda Guerra Mundial, com maior ênfase para o continente africano, conforme demonstrado pelo Gráfico 1.

Gráfico 1 - Chegadas internacionais de turismo por região mundial

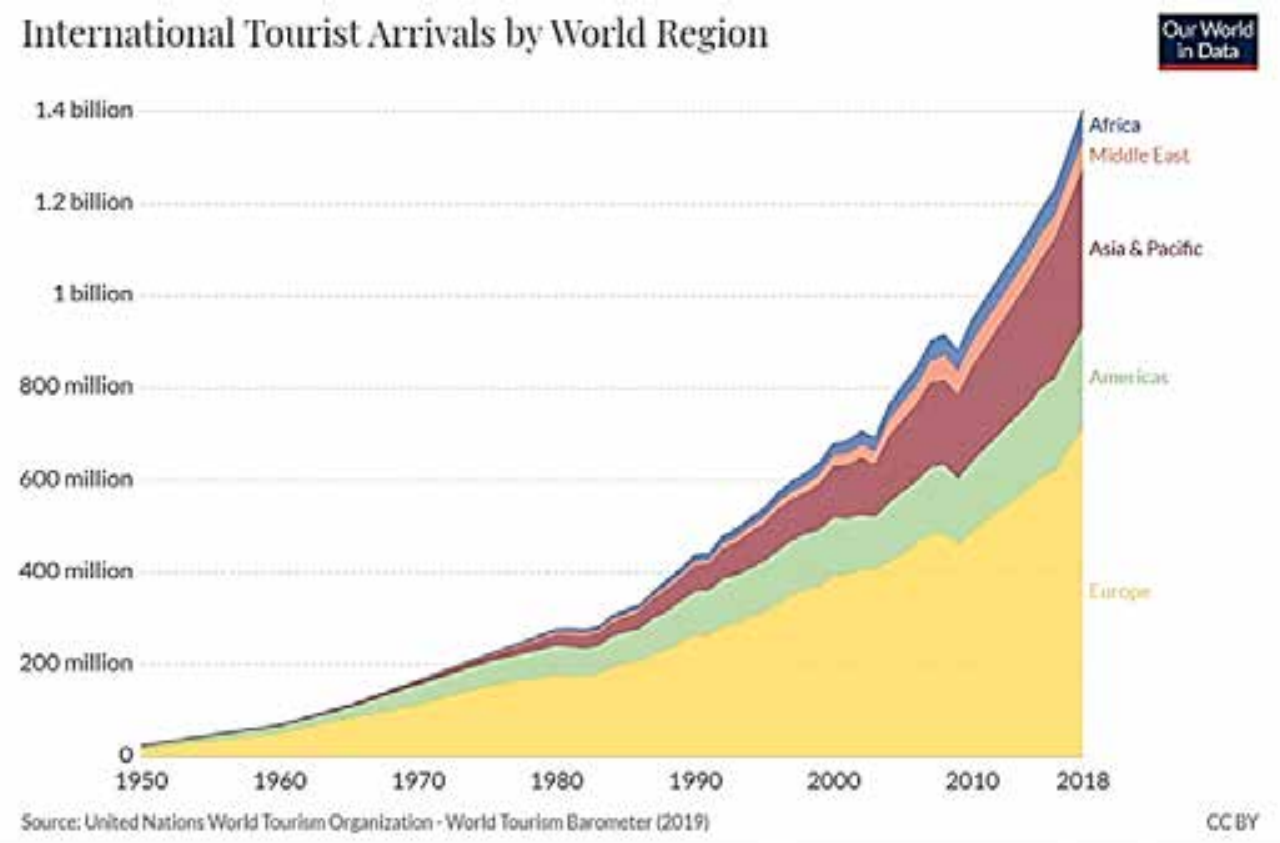

Fonte: ROSER, 2017.

\footnotetext{
${ }^{19}$ A exemplo do que acontece com as Ilhas Galápagos, que passam por uma séria crise de (in)sustentabilidade pela enorme densidade populacional turística que visita a região, em conformidade com WEARING; NEIL (2014).

${ }^{20}$ World Tourism Organization.
} 
A chegada de turistas alcançaram, em 2018, o número de 1,4 bilhões de pessoas nos diversos continentes numa perspectiva internacional. Esse aumento gradativo teve início no pós-Segunda Guerra Mundial na década de 50 e, desde então, até ao ano de 2018, esse aumento é muito expressivo, representando um aumento de 58 vezes numa visão comparativa com o ano de 1950.

\section{ECOTURISMO COMO ATIVIDADE DO FUTURO SUSTENTÁVEL}

Com a crescente degradação dos espaços naturais, o ecoturismo surgiu como atividade turística para a solução de preocupações que surgem de diversas ordens - social, ambiental e econômica -, voltadas à conscientização para a necessidade da proteção de espaços verdes e da sua diversidade biológica, como alternativa ao turismo convencional. Diante das variadas conceituações que vêm sendo dadas ao termo, o mesmo pode ser encarado como turismo natural, turismo verde, turismo ecológico, turismo ambiental, turismo cultural, turismo na natureza e turismo sustentável.

Figura 1 - Relação entre os 12 pilares da sustentabilidade

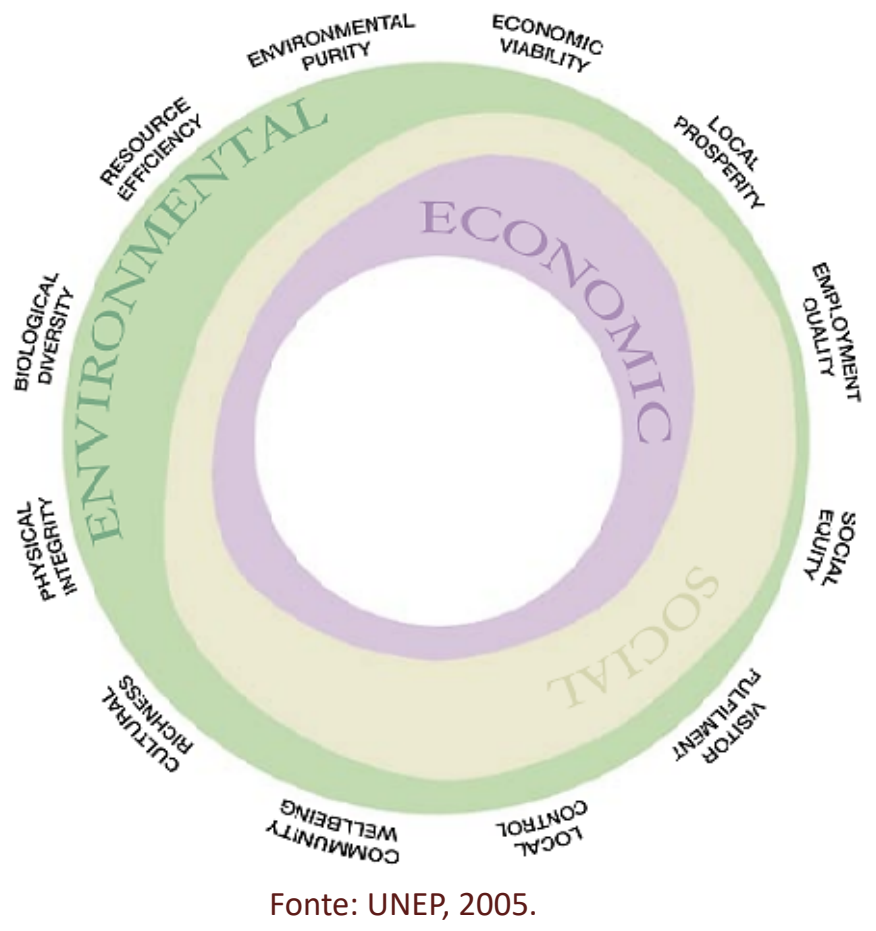

A Figura 1 apresenta a inter-relação entre as abordagens da sustentabilidade com base nas dimensões social, ambiental e econômica. ${ }^{21} \mathrm{~A}$ agenda para o turismo sustentável prevê, como itens base para o ecoturismo, a capacidade de o turismo ser encarado como atividade do futuro e a capacidade da sociedade e o meio ambiente absorverem os impactos e benefícios da atividade. Para que tal seja possível, a minimização dos impactos negativos e a maximização da contribuição positiva e criativa do turismo para as comunidades locais, e a conservação dos patrimônios cultural, natural e histórico, devem ser almejados.

São 12 os objetivos que o turismo sustentável procura desenvolver, quais sejam: a viabilidade econômica (competitividade e prosperidade); prosperidade do local (desenvolvimento das comunidades locais); qualidade do emprego (remuneração, condições de saúde, não discriminação); equidade social (distribuição justa e ampla dos benefícios); cumprimento do visitante (proporcionar a melhor experiência no meio natural); controle local (planejamento, gestão e controle das comunidades locais); bem-estar comunitário (qualidade de vida, harmonização nas comunidades); riqueza cultural (valorização dos patrimônios histórico e cultural das

\footnotetext{
${ }^{21}$ Para aprofundamento em todas as dimensões do desenvolvimento sustentável, especialmente a jurídico-política como forma de assegurar os direitos fundamentais intergeracionais, ver: GOMES; FERREIRA, 2017, p. 93-111.
} 
comunidades); integridade física (das paisagens, valorização do urbano e rural); diversidade biológica (apoio à conservação das áreas naturais, habitats e vida selvagem); eficiência de recursos (minimização do uso de energias não renováveis/escassas); pureza ambiental (minimização de poluição de ar, água e da Terra). ${ }^{22}$

$\mathrm{O}$ ecoturismo tem potencial de resolver problemas ligados à pobreza e à desigualdade social numa comunidade global em que, segundo dados de 2019 da The International Ecotourism Society (TIES), 130 milhões de pessoas vivem em extrema pobreza e 1 em cada 9 não tem alimento para que as suas vidas possam ser consideradas dignas, com a adoção de um estilo de vida saudável e ativo (THE INTERNATIONAL..., 2019). No mesmo sentido, o turismo representa, atualmente, 9\% do Produto Interno Bruto (PIB) mundial, 1 em cada 12 empregos e $29 \%$ das exportações de serviços, o que se reflete numa melhoria das condições de vida a curto e longo prazos.

De outro lado, o ecoturismo pode resultar num efeito contrário àquele que se pretende no tocante às emissões de GEE em razão da construção de infraestruturas para meios de transporte, construção de hotéis, estradas, restaurantes e de saneamento. Pode ser encarado, segundo Pires (1998), como uma "rotulação" para atividades que respeitam o meio ambiente na sua forma natural e de acordo com um viés preservacionista e conservacionista, tendo em vista a menor intervenção possível que se almeja nesses espaços.

Assim, as áreas de atuação do ecoturismo prendem-se com a sustentabilidade ambiental, cultural, social e econômica, com a conscientização para a conservação por meio da educação ambiental, esta última como "uma das maneiras em prol de disseminar a necessidade de preservação da natureza" e "instrumento universal de combate à degradação do meio ambiente" (GOMES; CARVALHO, 2018, p. 18-20), além de promover o convite à comunidade local a participar de iniciativas com a "natureza elevada à condição de motivadora primordial da iniciativa turística, em seu estado natural sem alterações humanas significativas" (PIRES, 1998, p. 88).

O ecoturismo surge, portanto, incorporado à preservação da cultura, da história e dos recursos naturais.

\subsection{Base Principiológica do Turismo Sustentável pela Organização das Nações Unidas e Organização Mundial do Turismo}

É de suma importância que se tenha em mente os 12 princípios pelos quais o turismo sustentável se desenvolve. O primeiro deles está relacionado com a necessidade de uma visão holística por parte do desenvolvimento com o turismo sustentável. Deve-se, aqui, considerar os impactos dessa atividade e, com base nisso, desenvolver-se políticas públicas que atendam a esses impactos. Sem o engajamento das partes envolvidas, comunidades locais e ecoturistas, não há qualquer contribuição para o desenvolvimento da atividade, pelo que é essencial uma atuação conjunta. O planejamento em longo prazo permitirá que, quando abordados os impactos locais e globais, se desenvolvam políticas relacionadas com mudanças climáticas, poluição por disposição de resíduos e utilização de recursos não renováveis.

Do que foi dito anteriormente, surge a necessidade de conscientizar o ecoturista para o consumo sustentável que vai muito além da escolha de produtos, passando pelos modos de viajar escolhidos, pelas suas atividades e comportamentos no meio natural, procurando se igualar a sustentabilidade com a qualidade, a qual passa pela própria escolha do local turístico a visitar.

Um dos princípios que rege o turismo sustentável é o princípio do poluidor-pagador, segundo o qual, aquele que causa dano ambiental deve incorrer nos custos necessários para a reposição da situação que existia antes do dano. No mesmo viés principiológico, o princípio da precaução é aplicável na minimização dos riscos quando há conhecimento de que determinada situação pode acarretar danos significativos para o meio ambiente, por meio da tomada de medidas que visem a evitar tal dano.

Numa perspectiva de sustentabilidade a longo prazo, o impacto que um determinado produto pode acarretar no futuro daquele ambiente, seja com base na localização, desenvolvimento da região, construção, uso e descarte de materiais, deve ser seriamente analisado antes de ser efetivado ou empregado, uma vez que a utilização de materiais alternativos pode resultar em uma solução, posto que um produto mais sustentável pode promover os mesmos resultados esperados e ser menos impactante para o meio natural.

$\overline{22}$ UNEP, 2005, p. 18-19. 
Para que a área verde não sofra a massificação turística, é imprescindível que se respeitem os limites da capacidade de carga do lugar, a qual se relaciona diretamente com o fluxo ou volume turístico que um espaço está apto a receber sem que a sua capacidade de resiliência seja afetada. Esses limites levam em consideração os recursos naturais, as comunidades locais, a satisfação dos visitantes, entre outras questões.

A adaptação às condições das mudanças climáticas, ameaças globais, aquecimento global e terrorismo, necessita ser previamente desenvolvida como riscos ao turismo futuro nas políticas de gerenciamento da atividade, do mesmo modo que o monitoramento contínuo, usando bons indicadores, é fundamental. Segundo o United Nations Programme and World Tourism Organization (2005), essa boa gestão exige que, ante a eventuais mudanças de diversos pontos, existam ajustes nas políticas e nas ações, procurando desenvolver os diversos objetivos e metas que permitam o monitoramento nessas condições, como o monitoramento econômico.

\subsection{Planejamento Ecoturístico em Áreas Naturais de Preservação}

Para que projetos e empreendimentos sejam bem-sucedidos, é necessário que, antecipadamente, se faça um planejamento integral cuidadoso, tanto em âmbito físico quanto gerencial. É necessária a criação de diretrizes e de regulamentos que garantam um eficaz e eficiente funcionamento.

Segundo Lascuráin (apud LINDBERG; HAWKINS, 2005, p. 27), o ecoturismo é considerado um "fenômeno complexo e multidisciplinar" precisamente pelo planejamento e pelos critérios que devem ser considerados no tocante à viabilização, construção de infraestruturas, estradas, capacidade de enfrentamento na falta de orçamento, ausência de mão de obra especializada, estimulação das comunidades locais e inventários das diversas atrações turísticas que o espaço tem a oferecer.

As "ecotécnicas", técnicas ambientalmente sustentáveis e responsáveis, são essenciais no tocante à infraestrutura e à captação, reutilização e reciclagem de resíduos e de água, uma vez que é um tipo de construção que considera a utilização de técnicas e de materiais nativos que devem ser utilizados para que a interferência no habitat seja sentida o mínimo possível.

Como meio alternativo de desenvolvimento sustentável e a outras formas de crescimento econômico, o ecoturismo pode deparar-se com a problemática de, na geração de empregos e, por consequência, renda, gerarem-se divisas entre os povos da comunidade pelo crescimento regional que se alcança com o turismo sustentável. Em alguns casos essa divisão nas comunidades foi mais sentida do que o crescimento do PIB.

Apesar disso, o turismo tem-se revelado, desde 2008, um dos motores do crescimento econômico em âmbito mundial. Conforme a Figura 2, o crescimento econômico aumenta em sentido proporcional ao crescimento do turismo.

Figura 2 - Contribuição total e direta das viagens para turismo na economia global de 2006 a 2018 (em trilhões de dólares)

Direct and total contribution of travel and tourism to the global economy from 2006 to 2010 (in trillion U.S. dollars)

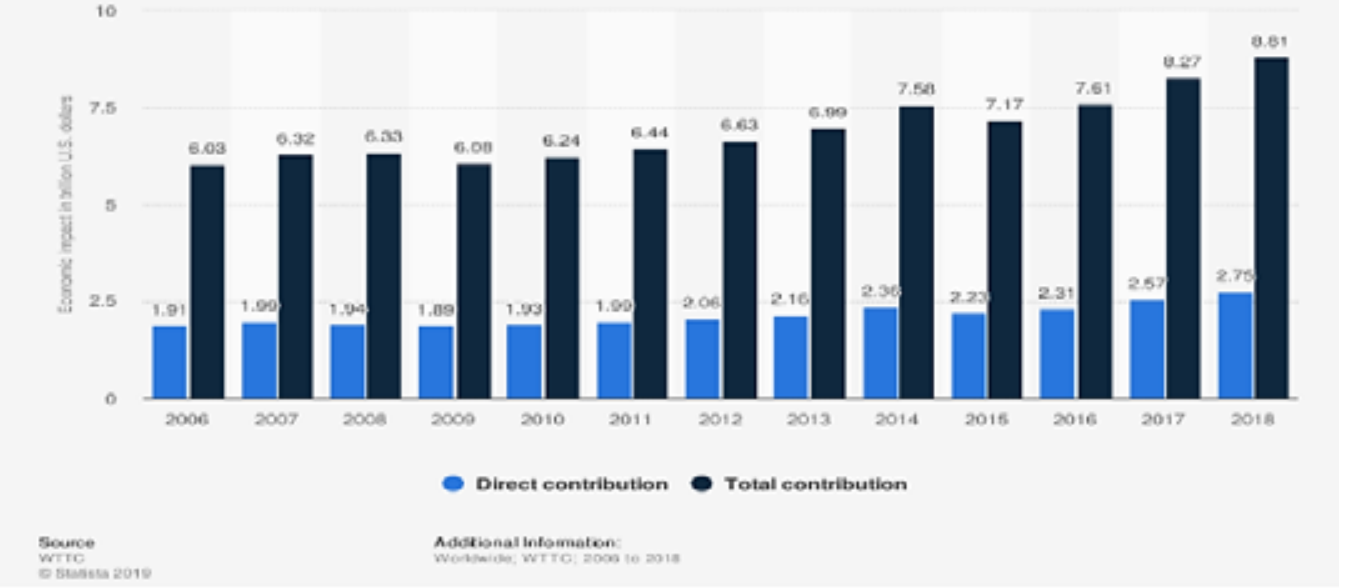

Fonte: STATISTA, 2018. 
Percebe-se também que o ecoturismo cresce um pouco mais a cada ano, gerando, no ano de 2018 , a quantia de US\$ 8.81 trilhões num total de contribuição, US\$2.78 trilhões a mais do que no ano de 2008.

São ainda considerados impactos ambientais o aumento da poluição, a elevação dos preços e a exportação dos lucros, a pressão sobre espécies ameaçadas de extinção e a distribuição desigual dos benefícios auferidos na atividade promovida por aquela região.

No planejamento e na construção de diretrizes e regras, para que as comunidades locais se integrem verdadeiramente na atividade e abracem a causa da sustentabilidade, elas precisam ter a segurança dos benefícios investidos na sua comunidade para melhoria da saúde, construção de escolas, acesso a tratamento hospitalar e mais qualidade das condições de vida. Sem essa confiança, as comunidades não estarão dispostas a fazer tantos esforços e a sofrer todos os impactos.

Deste modo, não é concebível que as populações não tenham acesso a informações relacionadas com o produto econômico do trabalho desenvolvido pela atividade. Do mesmo modo, a falta de infraestruturas e de competências especializadas, que poderão ter diversas origens, prejudicarão a atividade e, por consequência, será necessária a importação de mão de obra, infraestruturas e tecnologias, bens e serviços. Corroborando esse pensamento, Garcia (2016) desenvolve que

Essa economia vem alicerçada em três pilares: o pilar econômico, segundo o qual o crescimento deverá manter-se em níveis mais elevados que os atuais, com protecionismo verde; o pilar social, que é o mais discutido e está ligado à necessidade de diminuição da pobreza e à geração de emprego; e o pilar ambiental, ligado à necessidade de mudanças nos modos de produção e consumo, em direção a um modelo sustentável, com a necessária "revolução tecnológica" (GARCIA, 2016, p. 142).

É importante que se tenha em mente que o investimento auferido não será breve e rápido, mas de longo prazo, pelo que a comunidade deve se manter unida e atualizada com relação aos progressos e retrocessos. Por norma, os benefícios econômicos de caráter imediato não ficam nas comunidades, mas são destinados aos cofres do Estado. Os custos sociais e ambientais, entretanto, ficam, de modo mais austero, a cargo da comunidade.

O papel governamental é fundamental para a efetivação do ecoturismo pelo fato de que "o governo é o único órgão que pode oferecer planejamento e administração em longo prazo, como proteção legal e jurídica das reservas naturais para o benefício das futuras gerações" (WEARING; NEIL, 2014, p. 45). Dessa forma, é importante o desenvolvimento da confiança por parte das comunidades locais.

Por meio de projetos eficientes e de planejamento que considerem de fato a sustentabilidade e que se comprometam com iniciativas conservacionistas, serão gerados empregos e receita financeira que beneficiarão as comunidades e o Estado Nacional. Por isso, é imprescindível uma atitude de iniciativa positiva por parte do governo nacional, por exemplo, por meio de PPPs que almejem alojamento, transporte e hotelaria, setores nos quais as perdas dos países em desenvolvimento no atendimento a essas especificidades se concentram na casa dos $80 \%$ e $90 \%$.

Corroborando o que foi dito, Wearing e Neil (2014) argumentam que "para que o turismo não ultrapasse sua base sustentável, é fundamental entender os mecanismos que levam à provisão da infraestrutura para o desenvolvimento e dos pré-requisitos políticos e institucionais para o planejamento e a administração do ecoturismo" (p. 41), para que o planejamento seja eficaz e aumente a possibilidade do desenvolvimento sustentável. A conscientização do potencial natural será o próximo passo a ser dado, uma vez que o desenvolvimento apenas será sustentável se atender às demandas do desenvolvimento da comunidade com as necessidades do meio ambiente e, por isso, a urgência de equilibrar todas as suas dimensões, alcançando o plexo da sustentabilidade.

\subsection{Definição de Diretrizes para o Diagnóstico e Planejamento do Ecoturismo e a Participação Social}

Na pesquisa desenvolvida pela $\operatorname{Ties}^{23}$ no ano de 2019, os entrevistados colocaram como principais desafios, atualmente enfrentados pelo ecoturismo, o superdesenvolvimento, a falta de conhecimento e de consciência, as mudanças climáticas, ${ }^{24}$ a dificuldade de autorizações e de financiamento, o turismo excessivo (massificação) e a falta de capacidade nas reservas de uma forma justa (THE INTERNATIONAL..., 2019).

\footnotetext{
${ }^{23}$ Sociedade Internacional de Ecoturismo (Tradução nossa).

${ }^{24}$ As populações mais sensíveis às mudanças climáticas, segundo o relatório da ONU, Global Sustainable Development Report 2019, são as 900 milhões de pessoas que vivem em regiões montanhosas no mundo.
} 
Para que esses problemas ou parte deles sejam resolvidos, é necessário planejamento, desenvolvimento de consciência e mudança de valores no modo como a natureza é percebida.

Dados de 2019 da Ties revelaram que 41\% dos entrevistados acreditam na educação como setor a ser priorizado, $18 \%$ focam na conservação, mudança climática e parcerias no âmbito da conservação, $14 \%$ nas ecodestinações, $11 \%$ em publicações e $9 \%$ na mídia social. Poucos foram os entrevistados que citaram políticas públicas como um foco importante a ser trabalhado, assim como parcerias com a ONU (THE INTERNATIONAL..., 2019). ${ }^{25}$

A participação social global assume um fator cada vez mais essencial no desenvolvimento do ecoturismo, sem a qual não é possível alcançar os ODSs propostos para as décadas de 20 e 30 do século 21 . Nesse panorama, o atual Secretário-Geral da OMT, Zurab Pololikashvili, sustenta que

Gerenciar o turismo de maneira sustentável para o benefício de todos é mais crítico do que nunca. Precisamos crescer mais em valor do que apenas em volume. Espera-se que digitalização, inovação, maior acessibilidade e mudanças na sociedade continuem moldando nosso setor. Tanto os destinos quanto as empresas precisarão se adaptar para permanecer competitivos e, ao mesmo tempo, abraçar o turismo como meio de alcançar os Objetivos de Desenvolvimento Sustentável e construir um futuro melhor para todos (UNWTO, 2019, p. 2) (tradução nossa). ${ }^{26}$

Para que a atividade do ecoturismo não represente prejuízos para a área que se pretende preservar e para que o crescimento dessa atividade não se torne insustentável, resultando em prejuízos para as áreas naturais e comunidades vizinhas, devem ser desenvolvidas algumas orientações prévias, conforme afirmado por Boo (2005):

A estratégia deverá guiar o desenvolvimento e a gestão do ecoturismo, a fim de assegurar que a área protegida não seja excessivamente ocupada nem destruída por turistas, de criar mecanismos capazes de gerar empregos e renda para a área protegida e para as comunidades próximas e de oferecer educação ambiental aos visitantes (p. 37).

No ecoturismo, o desenvolvimento de parcerias entre empresas privadas, responsáveis pela promoção da experiência e entidades governamentais ou não governamentais responsáveis pela proteção das áreas verdes, deve proporcionar uma verdadeira experiência ao ecoturista, um real envolvimento e contato com o meio natural. Além disso, deve promover recursos para a manutenção e gestão dessas áreas, encaminhar benefícios para as populações das comunidades locais, estimular a tolerância e o respeito ante as culturas com as quais os ecoturistas estarão em contato direto e procurar promover o menor impacto humano possível no ambiente.

\section{CONSIDERAÇÕES FINAIS}

O ecoturismo surgiu como alternativa ao turismo de massa ou convencional, pela continuada degradação ao meio natural e como alternativa para o desenvolvimento dos países, nas suas dimensões ambiental, social e econômica, conscientizando as pessoas acerca da necessidade da mudança comportamental com relação ao ambiente.

A EU e o Mercosul desenvolveram nas suas políticas mecanismos de preservação e conservação ambiental que se destacam no campo da gestão e do planejamento, assim como o manejo sustentável dos recursos, tratamento residual e a criação de atividades produtivas e ambientalmente sustentáveis entre os Estados signatários.

\footnotetext{
${ }^{25}$ Tradução livre de: "The most surprising opinions, for us, came from a question about what initiatives TIES should be supporting. 41\% of the respondents requested that we focus on education, $18 \%$ told us to focus on conservation, climate change and conservation partnerships, $14 \%$ told us to focus on ecodestinations, wherein we describe national ecotourism offerings by country, $11 \%$ told us to focus on publications, and 9\% told us to focus on social media. Very few requested we work on policy, UN partnerships, ecotraveler focus, and only six respondents suggested we focus on increasing membership. We have reached out to several partners in the education space, and we'll detail our plans in the coming month" (THE INTERNATIONAL..., 2019).

${ }^{26}$ Tradução livre de: "Managing tourism in a sustainable manner for the benefit of all is more critical than ever. We need to grow more in value rather than just in volume. Digitalization, innovation, greater accessibility and societal changes are expected to continue shaping our sector. Both destinations and companies will need to adapt to remain competitive, while at the same time embracing tourism as a means of achieving the Sustainable Development Goals and building a better future for all" (UNWTO, 2019, p. 2).
} 
O ecoturismo desenvolveu-se a partir do momento em que se tornou necessário repensar a corrente tecnicista e tecnológica dos recursos naturais como meros meios para o alcance dos fins benéficos aos seres humanos e em detrimento das atrocidades que vinham sendo cometidas contra o meio natural. A tecnologia pode ser uma aliada na sustentabilidade se houver uma mudança de valores e de comportamentos acompanhada desse processo evolutivo, que considere a natureza na sua visão holística e preservacionista.

O ecoturismo pode ser, sim, considerado a atividade do futuro preservacionista do meio ambiente, instrumento de manutenção do meio natural, se os seus objetivos forem seguidos pelas comunidades e governos locais pelo seu potencial conservacionista e gerador de renda, apesar dos impactos que a ela estão associados. Para tanto, o planejamento e gerenciamento são essenciais e devem ser encarados com seriedade pelos governos e sua população. Além disso, deve ser fomentado o ecoturismo nas políticas públicas e nos projetos que serão criados e desenvolvidos.

Apesar dos seus impactos ambientais relacionados com a construção de infraestruturas como estradas, hotéis, restaurantes e instalações turísticas, existem benefícios associados à conservação do meio ambiente por intermédio da mudança dos valores e como instrumento de financiamento para a proteção de áreas naturais. Os impactos socioculturais podem ser sentidos pelas comunidades na interação cultural, o que pode resultar mudanças comportamentais que ameacem a identidade da comunidade, mas há o benefício da criação de empregos para a população e crescimento econômico que se reflete no desenvolvimento econômico nacional.

Por tudo o que foi dito, o ecoturismo é um meio viável para que se alcance o desenvolvimento sustentável, se o direito comunitário continuar a desenvolver diretrizes nesse sentido e se os governos instituírem medidas e políticas que considerem as culturas locais e as suas comunidades de forma que essa seja uma ação conjunta que poderá trazer benefícios para todos os envolvidos enquanto pertencentes a um meio natural uno e indivisível.

\section{REFERÊNCIAS}

BARBERI, José Carlos. Gestão ambiental empresarial: conceitos, modelos e instrumentos. 3. ed. São Paulo: Saraiva, 2011.

BOO, Elizabeth. O planejamento ecoturístico para áreas protegidas. In: LINDBERG, Kreg; HAWKINS, Donald E. (org.). Ecoturismo: um guia para planejamento e gestão. 5. ed. São Paulo. Senac, 2005.

BRASIL. Ministério do Meio Ambiente. Compromissos estabelecidos na Convenção-Quadro das Nações Unidas sobre mudança do clima (UNFCCC). Ministério do Meio Ambiente, Brasília, Disponível em: https://www.mma.gov.br/component/k2/item/ 15142-contribui\%C3\%A7\%C3\%B5es-para-o-documento-base.html. Acesso em: 3 dez. 2019.

BRASIL. Ministério do Meio Ambiente. Convenção sobre diversidade biológica. Ministério do Meio Ambiente, Brasília, 2000. Disponível em: https://www.mma.gov.br/estruturas/sbf_dpg/_arquivos/cdbport.pdf. Acesso em: 20 out. 2019.

CERON, Lucas Freier; PORTO, Lucas Porciuncula. Convenção-quadro das Nações Unidas: Protocolo de Kyoto e a Polícia Nacional sobre Mudança do Clima. Revista Eletrônica do Curso de Direito, Santa Maria, v. 8, p. 529-540, 2013. Disponível em: https:// periodicos.ufsm.br/index.php/revistadireito/article/view/8368. Acesso em: 27 abr. 2020.

COMISSÃO EUROPEIA. A União Europeia e a Gestão dos Resíduos. Luxemburgo: Serviço das Publicações Oficiais das Comunidades Europeias, 2000. Disponível em: https://ec.europa.eu/environment/waste/publications/pdf/eufocus_pt.pdf Acesso em 23 out. 2019.

COMUNIDADE EUROPEIA. Directiva 94/62, de 20 de dezembro de 1994. Relativa a embalagens e resíduos de embalagens. Parlamento Europeu e Conselho da União Europeia, 31 dez. 1994. Disponível em: https://eur-lex.europa.eu/LexUriServ/LexUriServ.do?uri=CONSLEG:1994L0062:20130228:PT:PDF. Acesso em: 24 out. 2019.

GARCIA, Denise Schmitt Siqueira. Dimensão Económica da sustentabilidade: uma análise com base na economia verde e a teoria do decrescimento. Revista Veredas do Direito, Belo Horizonte, v. 13, n. 25, p. 133-153, jan./abr. 2016. Disponível em: http:// revista.domhelder.edu.br/index.php/veredas/article/view/487. Acesso em: 3 dez. 2019.

GOMES, Magno Federici; CARVALHO, Vânia Ágda de Oliveira. Educação ambiental e sua normatividade simbólica. Revista Jurídica UNI7, Fortaleza, v. 15, n. 1, p. 13-28, jan./jun. 2018. Disponível em: http://www.uni7.edu.br/periodicos/index.php/revistajuridica/article/view/254. Acesso em: 3 dez. 2019.

GOMES, Magno Federici; FERREIRA, Leandro José. A dimensão jurídico-política da sustentabilidade e o direito fundamental à razoável duração do procedimento. Revista do Direito, Santa Cruz do Sul, n. 52, v. 2, p. 93-111, maio/set. 2017. Disponível em: http://dx.doi.org/10.17058/rdunisc.v2i52.8864. Acesso em: 2 abr. 2020. 
GOMES, Magno Federici; FERREIRA, Leandro José. Políticas públicas e os objetivos do desenvolvimento sustentável. Revista Direito e Desenvolvimento, João Pessoa, v. 9, n. 2, p. 155-178, ago./dez. 2018. Disponível em: https://doi.org/10.25246/direitoedesenvolvimento.v9i2.667. Acesso em: 2 abr. 2020.

HARDIN, Garrett. The tragedy of the commons. Science, Cambridge-UK, v. 162, p. 1.243-1.248, dez. 1968. Disponível em: http://www.sciencemag.org/content/162/3859/1243.full.pdf. Acesso em: 1음 maio 2020.

HOLMES, Bob. Dangers of ecotourism: up close and infectious. Knowable Magazine, Palo Alto, 15 out. 2018. Society. Disponível em: https://www.knowablemagazine.org/article/society/2018/dangers-ecotourism-close-and-infectious. Acesso em: 2 nov. 2019.

JONGE, Eccy de. Spinoza and deep ecology: challenging traditional approaches to environmentalism. Farnham, Surrey-UK: Ashgate Publishing, 2004.

LINDBERG, Kierg; HAWKINS, Donald E. Ecoturismo: um guia para planejamento e gestão. 5. ed. São Paulo: Senac, 2005.

MACHADO, Cimara Corrêa et al. A agenda 21 como um dos dispositivos da educação ambiental. Ambiente \& Educação, Rio Grande, v. 12, p. 99-113, 2007. Disponível em: http://repositorio.furg.br/handle/1/6790. Acesso em: 27 abr. 2020.

NAÇÕES UNIDAS BRASIL. Transformando Nosso Mundo: a Agenda 2030 para o desenvolvimento sustentável. Nações Unidas, 12 out. 2015. Disponível em: https://nacoesunidas.org/pos2015/agenda2030/. Acesso em: 21 de nov. 2019.

PARLAMENTO EUROPEU. Acto Único Europeu (AUE). Sobre o parlamento, 10 jul. 1987. Disponível em: https://www.europarl. europa.eu/about-parliament/pt/in-the-past/the-parliament-and-the-treaties/single-european-act. Acesso em: 22 nov. 2019.

PIRES, Paulo dos Santos. A dimensão conceitual do ecoturismo. Turismo - Visão e Ação, Balneário Camboriú, v. 1, n. 1, p. 7591, jan./jun. 1998. Disponível em: https://siaiap32.univali.br/seer/index.php/rtva/article/view/1392. Acesso em: 25 nov. 2019. RILEY, Geoff. Tourism and Economic Development in Africa. Tutor2u, África, 26 nov. 2015. Economia. Disponível em: https:// www.tutor2u.net/economics/blog/tourism-and-economic-development-in-africa. Acesso em: 12 nov. 2019.

ROSER, Max. Tourism: International arrivals by world region. Our World in Data, 2017. Disponível em: https://ourworldindata. org/tourism. Acesso em: 1ำ nov. 2019.

STATISTA. Direct and Total Contribution of Travel and Tourism to the Global Economy from 2006 to 2018. Statista.com, 2018. Disponível em: https://www.statista.com/statistics/233223/travel-and-tourism--total-economiccontribution-worldwide/. Acesso em: 19 nov. 2019.

SUSTAINABLE Development of tourism. World Tourism Organization, 2019. Disponível em: https://sdt.unwto.org/content/ about-us-5. Acesso em: 8 nov. 2019.

THE INTERNATIONAL ECOTOURISM SOCIETY. Responses to the International Ecotourism Society's September 2019 Survey, 25 set. 2019. Disponível em: https://ecotourism.org/news/responses-to-the-international-ecotourism-societys-september-2019-survey/. Acesso em: 10 maio 2020.

THE STATE OF ECOTOURISM. The Internacional ecotourism, 15 jul. 2019. News. Disponível em: https://ecotourism.org/news/ the-state-of-ecotourism/. Acesso em: 12 nov. 2019.

UNITED NATIONS. Global sustainable development report 2019: The future is now: Science for achieving sustainable development. Science for Achieving Sustainable Development, New York, 2019. Disponível em: https://sustainabledevelopment. un.org/content/documents/24797GSDR_report_2019.pdf. Acesso em: 5 nov. 2019.

UNEP. United Nations Programme and World Tourism Organization. Making tourism more sustainable: a guide for policy makers. Haya: Unep, 2005. Disponível em: http://www.unep.fr/shared/publications/pdf/DTIx0592xPA-TourismPolicyEN.pdf. Acesso em: 9 nov. 2019.

UNITED NATIONS. Our Common Future. 1987. Disponível em: file:///C:/Users/joana.goncalves/Downloads/our_common_futurebrundtlandreport1987.pdf. Acesso em: 2 dez. 2019.

UNWTO. International Tourism Highlights. 2019. Disponível em: https://www.e-unwto.org/doi/pdf/10.18111/9789284421152. Acesso em: 4 nov. 2019.

WEARING, Stephen; NEIL, John. Ecoturismo: impactos, potencialidades e possibilidades. 2. ed. São Paulo: Manole, 2014. 